A Lead Children's Cancer nurse, from a different region, heard about the module and approached me to see if the module could be delivered 'off campus' to meet her local need. ELearning has been used to offer education across regional and international boundaries but the lead nurse was very keen to encourage face to face networking of tertiary centre nurses, shared care hospital nurses and community nurses.

Contracts were negotiated between the Regional education commissioner and my university. I delivered the module at the Tertiary centre and attracted 14 students from the region. Specialist speakers from the Tertiary centre willingly contributed to the timetable as it was on their 'doorstep'.

The evaluation of the module was very positive e.g.

"Already taken knowledge gained from this course back to practice"

"Great to discuss all aspects of treatment and care from tertiary, acute, DGH and community perspectives"

This has been a worthwhile collaboration which has evaluated well and enabled appropriate education to be delivered 'closer to home'. Hopefully it will happen again next year!

\section{G211 BREAKING BAD NEWS: DIFFICULT UNDERTAKING FOR HEALTHCARE PROFESSIONALS}

DAP Corkin, R Hollis. C\&YP Specialist Forum, Royal College of Nursing, London, UK

\subsection{6/archdischild-2015-308599.205}

Aims An evidence-based document ${ }^{1}$ and journal article ${ }^{2}$ are advocating effective strategies for nurses and doctors to utilise when supporting parents receiving 'bad news' as well as communication with children and young people during this difficult undertaking. Discussion outlines quality resources that will equip healthcare professionals in their practice. Nurses should aim to apply this guidance when undertaking this complex and challenging aspect of care.

Methods Delegates will be directed to communication frameworks, which are the product of a rigorous literature search of electronic databases and exhaustive consultation across four countries. Evidence suggests a variation in practice especially in the way in which parents are first given 'bad news' about their child's health. 'Bad news' may relate to a child's diagnosis or prognosis across a whole range of health and social care settings. Having significant or distressing news disclosed in a manner that lacks sensitivity or in an environment which is inappropriate may cause additional stress at what is likely to be a difficult time.

Results Developing the knowledge and skills of the pre-registrant student are important. A themed lecture with role-play outlining frameworks and communication of 'bad news' have their place in education. Ongoing evaluation within a University suggests that second year student nurses from within four fields of nursing have evaluated a timetabled teaching session very positively, commenting:

'that was one of those lectures that reminds you that you're in a privileged position as a nurse'

Also important to expose emerging healthcare professionals to inter-professional education and clinical areas where bad news' is given.

Conclusions Guidance assists nurses, midwives and health visitors to reflect upon their own experiences and to consider how their skills can improve ${ }^{1}$. This document has additional guidelines on Child and Adolescent Mental Health services (CAMHs) and Emergency Care, as it was recognised that there were some very specific issues to address in these settings. The need for further research is highlighted and the requirement for supportive education and training opportunities to enhance both nurse's and doctor's skills in this important, challenging area of everyday practice.

\section{REFERENCES}

1 RCN. Breakingbad news: supporting parents when they are told of their child's diagnosis. RCN guidance for nurses, midwives and health visitors. London; 2013

2 CrawfordD, Corkin D, Coad J, Hollis R. Educating children's nurses for communicating bad news. Nursing Children Young People 2013;25(8):28-33

\section{G212(P) THE EXPERIENCES OF NURSES CARING FOR CHILDREN ON PAEDIATRIC INTENSIVE CARE (PIC) WHO TRANSITION FROM CURATIVE TO END OF LIFE CARE: A LITERATURE REVIEW}

J Spry. Paediatric Intensive Care, Birmingham Children's Hospital, Birmingham, UK

10.1136/archdischild-2015-308599.206

Background The experiences of nurses caring for children in Paediatric Intensive Care (PIC) who transition from curative care to palliation and end of life care have the potential to be extremely varied and pose opportunities to be both a privilege and a challenge. A review of the literature was conducted to discover what may already be known about the experiences of nurses caring for children during this time of transition.

Method Medline, CINAHL, PsycINFO, Web of Science and ASSIA were searched. The databases were chosen to incorporate a variety of publications with differing disciplinary focus. $\mathrm{MeSH}$ and key search terms used included:

- Terminal care/Palliative care/end of life care

- Intensive care

- Paediatric/paediatric

Broad terms were used to capture as many articles as possible and were then checked visually for relevance.

Results 488 articles were identified, only 8 are included in the review. Reasons for exclusion included duplication focus on communication, education, interventions/change in practice, ethics or law.

Settings of the studies were adult intensive care and acute care, and paediatric oncology and acute care. From the 8 articles, the following themes arose:

- Making a diagnosis of dying and recognising the point of transition - knowing when the time is 'right' for a patient to transition to palliative or end of life care.

- Timing of transition and reaching a consensus

- Families - reaching a consensus, holding on to false hope

- Professional issues - emotional burden and crossing boundaries.

These all contribute to nurses experiencing frustration and increased levels of stress.

There are clear commonalities in these studies; however none specifically explore the experience of PIC nurses in the UK when caring for children transitioning to palliative or end of life care.

Conclusion There is a clear gap in the research in this area. There is a qualitative study in a regional PICU being undertaken which will begin to address this. 